\title{
Exigência de metionina+cistina para aves de reposição leves e semipesadas alimentadas de 5 a 11 semanas de idade com ração farelada e peletizada
}

\author{
Edson Lindolfo da Silva ${ }^{1}$, José Humberto Vilar da Silva ${ }^{2}$, Antônio Gilberto Bertechini ${ }^{1}$, Paulo \\ Borges Rodrigues ${ }^{1}$, Janaina Maria Batista de Sousa ${ }^{3}$, Marcelo Luís Gomes Ribeiro ${ }^{2}$
}

\author{
${ }^{1}$ Departamento de Zootecnia, DZO/UFLA - CEP: 37200-000 - Lavras, MG. Bolsista CNPq. \\ 2 Departamento de Agropecuária, DAP/UFPB - CEP: 58220-000 - Bananeiras, PB. Bolsista CNPq. \\ ${ }^{3}$ Departamento de Tecnologia Rural, DTR/UFPB - CEP: 58220-000 - Bananeiras, PB. Bolsista PIBIC/CNPq/UFPB.
}

RESUMO - Os objetivos neste trabalho foram reavaliar as exigências em metionina+cistina (met+cis total) de frangas leves e semipesadas de 5 a 11 semanas de idade, considerando a forma física das rações, e o desempenho no período de 22 a 40 semanas, fase de postura. Foram utilizadas 1.120 frangas (560 leves e 560 semispesadas) em delineamento inteiramente casualizado, em esquema fatorial $5 \times 2 \times 2$, com 20 combinações compostas de cinco níveis de met+cis total $(0,56$; 0,60; 0,64; 0,68 e 0,72), duas formas físicas da ração (farelada e peletizada) e duas linhagens (Dekalb White e Bovans Goldline), cada uma com quatro repetições de 14 aves. As rações basais foram suplementadas com DL-metionina (99\%) para conter cinco níveis de met+cis total, segundo recomendações da literatura nacional e do manual da linhagem. As rações experimentais do período de cria foram isocalóricas em EM (2.900 kcal/kg), e isonutritivas em PB (17\%), cálcio (1,00\%) e fósforo disponível $(0,45 \%)$ e continham 0,$56 ; 0,60 ; 0,64 ; 0,68$ ou 0,72 de met+cis total, enquanto, no período de produção, foi fornecida uma dieta única com $2.850 \mathrm{kcal} / \mathrm{kg}$ de EM, 16\% PB, 3,70\% de cálcio e 0,34\% de fósforo disponível. As aves semipesadas apresentaram melhor desempenho em comparação às leves. A dieta peletizada promoveu melhores consumos total e diário de ração em comparação à dieta farelada. Na fase de postura, os níveis de met+cis afetaram a produção, o peso e a massa do ovo e a conversão por massa de ovo. Os níveis de met+cis e a forma física da dieta durante o período de cria afetam o desempenho das aves na fase de produção. A linhagem leve tem maior desempenho. Recomendam-se níveis diários 320 e 364 mg de met+cis para aves leves e semipesadas, respectivamente.

Palavra-chave: aminoácido, forma física, período de cria, poedeiras comerciais

\section{Methionine+cystine requirements for light and semi-heavy replacement birds fed mashed or pelleted feeds}

ABSTRACT - The objective of this study was to reevaluate the requirements of Methionine+cystine (met+cis total) of light (L) and semi-heavy ( $\mathrm{SH}$ ) pullets at 5 to 11 weeks of age considering the physical shape of the feeds and the performance in the 22 to 40 week period, the laying phase. A total of 1,120 laying pullets (560 lightweight and 560 semiheavy) in a randomized completedesign in a $5 \times 2 \times 2$ factorial scheme with 20 combinations consisting of five total Met+Cys levels $(0.56 ; 0.60 ; 0.64 ; 0.68$ or 0.72 ), two physical shapes (mashed and pelleted) of the feed and two lines (Dekalb White and Bovans Goldline) each with four replications of 14 birds each. The basal rations were supplemented with DL-Met. (99\%) to provide five total Met+Cys levels according to the recommendations of the Brazilian literature and the line handbook. The experimental feeds of the growing period were isonutritive in ME (2,900 kcal/kg), CP (17\%), Ca $(1,000)$ and available $\mathrm{P}(0.450)$, containing total Met+Cy levels of $0.56 ; 0.60 ; 0.64 ; 0.68$ and 0.72 , while in the laying period, a single diet with $2,850 \mathrm{kcal} / \mathrm{kg} \mathrm{ME},(16 \%) \mathrm{CP},(3.70 \%)$ of $\mathrm{Ca}$ and $(0.340 \%)$ of available $\mathrm{P}$ was fed. The semiheavy birds performed better compared to the light birds. The pelleted feed provided better total and daily feed intakes compared to the mashed feed. In the laying phase, the Met+Cys levels affected production, egg weight and mass and conversion to egg mass. The levels of Met+Cys and the physical shape of the feed over the laying period affected the subsequent performance of the birds in the laying period. The light line performed best. Levels of 320 and $364 \mathrm{mg}$ Met+Cys daily are recommended for light and semi-heavy birds, respectively.

Key Words: amino acid, commercial laying hens, physical shape, rearing period 


\section{Introdução}

A atualização das exigências nutricionais de metionina+cistina para frangas no período de recria justifica-se pelo melhoramento genético contínuo e pelo surgimento de novas linhagens com características de produção superiores às já existentes no mercado. As novas linhagens de postura apresentam baixo consumo de ração, alta eficiência alimentar e início precoce de postura, que coincide com o crescimento final da franga. Os planos de nutrição para aves em crescimento visam garantir a oferta de rações balanceadas, formuladas com ingredientes de alta qualidade e processadas adequadamente, visando melhorar a deposição de nutrientes no corpo, que serão mobilizados para garantir desempenho máximo durante todo o ciclo de postura.

Há alguns anos, recomendavam-se valores mais elevados de metionina+cistina para as duas linhagens (Rostagno et al., 2000), seguindo a mesma tendência do NRC (1994) de especificar níveis mais elevados desses aminoácidos para frangas leves na fase de 7 a 12 semanas $(0,55 \%)$ em relação às frangas semipesadas (0,53\%). Recentemente as especificações das tabelas anteriores foram alteradas (Rostagno et al., 2005), porém mantevese a tendência de recomendar valores mais elevados de metionina+cistina para frangas leves $(0,497 \%)$ em comparação às semipesadas $(0,489 \%)$, embora a diferença entre as duas linhagens seja cada vez menor.

Outras pesquisas com aminoácidos para poedeiras jovens parecem indicar menor diferença entre frangas de diferentes grupos genéticos. Silva et al. (2000b) observaram pequenas diferenças nas exigências de lisina entre frangas leves e semipesadas na fase de 7 a 12 semanas de idade. Por outro lado, ainda são escassos os trabalhos na literatura com avaliação da alimentação de frangas com rações peletizadas. Portanto, realizou-se este trabalho para reavaliar as exigências em metionina + cistina para frangas leves e semipesadas de 5 a 11 semanas de idade alimentadas com rações farelada e peletizada e analisar o desempenho no período de 22 a 40 semanas de idade.

\section{Material e Métodos}

O experimento foi conduzido no período de 12 de abril a 20 de dezembro de 2006 utilizando-se 1.120 aves: 560 frangas da linhagem leve Dekalb White e 560 frangas da linhagem semipesada Bovans Goldline, com cinco semanas de idade e peso vivo inicial de $288,45 \pm 7,45 \mathrm{~g}$ e $337,63 \pm 6,84 \mathrm{~g}$, respectivamente.
Depois de identificadas por tratamento, as aves foram pesadas e alojadas em boxes de 1,0 × 1,5 m, dispostos em duas fileiras e totalmente fechados com tela plástica à prova de pássaros; o piso era coberto com cama de maravalha e cada boxe continha uma lâmpada incandescente de 100 Watts, um comedouro tubular e um bebedouro pendular infantil. O galpão onde o experimento foi realizado era de alvenaria, medindo $24 \mathrm{~m}$ de comprimento e $9 \mathrm{~m}$ de largura, com orientação leste-oeste, laterais fechadas com telas de arame, muretas laterais de $0,40 \mathrm{~m}$ de altura, pé-direito de 2,80 m, sem lanternim e cobertura de telha de barro, apoiada em duas águas, com beirais de 1,50 m.

As condições ambientais de temperatura e umidade relativa do ar foram registradas duas vezes ao dia, utilizando-se um termohigrômetro digital pré-fixado no centro do galpão, na altura dos boxes. As médias de temperatura e umidade relativa do ar mínimas, médias e máximas foram, respectivamente, de 23,12; 25,09; $26,99^{\circ} \mathrm{C}$ e, 79,61; 91,92 e 97,98\% para o período de crescimento (12 de abril a 31 de maio de 2006).

Utilizou-se um delineamento inteiramente casualizado, com 20 tratamentos em esquema fatorial $5 \times 2 \times 2$, composto de cinco níveis de metionina+cistina total, duas formas físicas da ração e duas linhagens; cada nível de metionina + cistina com quatro repetições com 14 aves.

Uma dieta basal foi formulada para atender às exigências das aves em todos os nutrientes, segundo recomendações de Rostagno et al. (2005) e dos manuais das linhagens Dekalb White e Bovans Goldline (Granja Planalto, 2005a, b) (Tabela 1), exceto em metionina, que foi suplementada com DL-metionina (99\%) em substituição ao amido $(0,000 ; 0,040 ; 0,081 ; 0,121$ e $0,162 \%)$, resultando em cinco níveis de metionina+cistina total $(0,56 ; 0,60 ; 0,64$; $0,68$ e $0,72 \%)$.

Para estimativa da metionina+cistina total, foram considerados os valores totais desses aminoácidos nos ingredientes, de acordo com Rostagno et al. (2005). O nível intermediário de metionina+cistina total utilizado foi o recomendado pelo manual da linhagem. As dietas experimentais foram isocalóricas para energia metabolizável (2.900 kcal/kg de EM) e isonutritivas para proteína bruta (17\%), cálcio (1,00\%) e fósforo disponível (0,45\%). Foram adicionados $2,38 \%$ de caulim (inerte) à dieta para facilitar a agregação das partículas durante o processo de peletização.

As frangas receberam alimentação à vontade e foram submetidas a um programa de iluminação contínua (12 horas artificial + 12 horas de iluminação natural). O desempenho das frangas em crescimento no período de 5 a 11 semanas de idade foi avaliado quanto ao consumo total de ração, ao 
As somas de quadrados dos níveis de metionina+cistina foram desdobradas nos efeitos lineares, quadráticos, cúbicos e quadráticos, conforme procedimento do SAEG Sistema para Análises Estatísticas e Genéticas (UFV, 1993).

Tabela 2 - Composição da ração basal utilizada no período de produção para poedeiras leves e semipesadas ${ }^{1}$

\begin{tabular}{|c|c|}
\hline \multicolumn{2}{|c|}{ Ração basal } \\
\hline Ingrediente & $\%$ MS \\
\hline Milho & 64,997 \\
\hline Farelo de soja & 23,233 \\
\hline Calcário & 8,540 \\
\hline Fosfato bicálcico & 1,318 \\
\hline Óleo de soja & 0,970 \\
\hline DL-metionina & 0,223 \\
\hline L-lisina $\mathrm{HCl}$ & 0,068 \\
\hline Cloreto de colina & 0,050 \\
\hline Sal comum & 0,441 \\
\hline Premix vitamínico ${ }^{2}$ & 0,100 \\
\hline Premix mineral ${ }^{3}$ & 0,050 \\
\hline Antioxidante ${ }^{4}$ & 0,010 \\
\hline \multicolumn{2}{|l|}{ Composição nutricional } \\
\hline Proteína bruta (\%) & 16,34 \\
\hline Energia metabolizável (kcal/kg) & 2.849 \\
\hline Cálcio (\%) & 3,700 \\
\hline Fósforo disponível (\%) & 0,340 \\
\hline Metionina+cistina total (\%) & 0,756 \\
\hline Metionina+cistina digestível (\%) & 0,690 \\
\hline Metionina total (\%) & 0,482 \\
\hline Metionina digestível (\%) & 0,458 \\
\hline Lisina total (\%) & 0,862 \\
\hline Lisina digestível (\%) & 0,772 \\
\hline Treonina total (\%) & 0,628 \\
\hline Triptofano total (\%) & 0,190 \\
\hline Sódio (\%) & 0,210 \\
\hline \multicolumn{2}{|c|}{ 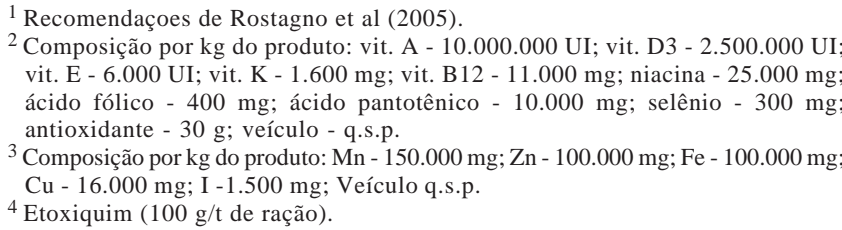 } \\
\hline
\end{tabular}

\section{Resultados e Discussão}

A uniformidade do peso corporal das aves foi de 91,57; 90,62; 83,31; 80,57 e 81,26\% para as aves leves e 66,$32 ; 58,31 ; 60,44 ; 62,25$ e $63,12 \%$ para as semipesadas, nos níveis de 0,56; 0,60; 0,64; 0,68 e 0,72\% de met+cis, respectivamente. Não houve efeito $(\mathrm{P} \geq 0,05)$ dos níveis de met+cis sobre os pesos-padrão das aves em experimento, entretanto os valores foram semelhantes aos observados nos manuais das duas linhagens.

A interação níveis de metionina+cistina total $\times$ linhagem $\times$ forma física da ração não teve efeito $(\mathrm{P} \geq 0,05)$ no peso corporal. Todavia, isoladamente, os níveis de metionina+cistina influenciaram $(\mathrm{P} \leq 0,001)$ o desempenho das aves (Tabela 3).

Pelo modelo de regressão polinomial $(\mathrm{P} \leq 0,001)$, os níveis de met+cis tiveram efeito significativo sobre o consumo de ração, total e diário, o ganho de peso total e diário e a conversão alimentar. As aves da linhagem semipesada apresentaram maior consumo de ração total e diário $(\mathrm{P} \leq 0,05)$ e melhores ganhos de peso total e diário $(\mathrm{P} \leq 0,05)$, mas tiveram pior $(\mathrm{P} \leq 0,05)$ conversão alimentar em comparação àquelas da linhagem leve. Os coeficientes de variação para os consumos de ração total e diário, os ganhos de peso total e diário e a conversão alimentar foram de 2,970; 2,181; 3,967; 2,302 e 3,023, respectivamente.

Os maiores consumos de ração total e diário foram obtidos com o nível de $0,65 \%$ de met+cis total (Figura 1 ), conforme as equações de regressão do consumo total de ração $\left(\hat{y}=-4149,7+26181 x-20130 x^{2} ; R^{2}=0,83\right)$ e do consumo diário de ração $\left(\hat{y}=-15,577+173,19 x-132,94 x^{2}\right.$; $\left.\mathrm{R}^{2}=0,94\right)$, independentemente da linhagem e da forma física da ração usada, no período de 5 a 11 semanas de idade.

O nível estimado de $0,65 \%$ de met+cis que promoveu os maiores consumos de ração total e diário é semelhante

Tabela 3 - Desempenho de frangas leves e semipesadas no período de 5 a 11 semanas de idade alimentadas com rações farelada ou peletizada contendo diversos níveis de metionina+cistina

\begin{tabular}{|c|c|c|c|c|c|}
\hline$\%$ met + cis & $\begin{array}{l}\text { Consumo total } \\
\text { de ração (g) }\end{array}$ & $\begin{array}{l}\text { Consumo diário } \\
\text { de ração (g) }\end{array}$ & $\begin{array}{l}\text { Ganho de peso } \\
\text { total (g) }\end{array}$ & $\begin{array}{l}\text { Ganho de peso } \\
\text { diário (g) }\end{array}$ & $\begin{array}{c}\text { Conversão } \\
\text { alimentar (kg/kg) }\end{array}$ \\
\hline 0,56 & 4211,2 & 47,1 & 1105,8 & 12,0 & 3,7 \\
\hline 0,60 & 4274,0 & 48,8 & 1233,4 & 13,1 & 3,6 \\
\hline 0,64 & 4402,3 & 49,4 & 1311,3 & 14,4 & 3,5 \\
\hline 0,68 & 4328,5 & 49,6 & 1249,3 & 13,9 & 3,6 \\
\hline 0,72 & 4266,9 & 48,4 & 1144,5 & 12,8 & 3,7 \\
\hline \multicolumn{6}{|l|}{ Linhagem } \\
\hline Leve & $4416,9 b$ & $49,3 b$ & $1129,7 b$ & $12,5 b$ & $3,9 a$ \\
\hline $\begin{array}{l}\text { Semipesada } \\
\text { Forma física }\end{array}$ & $5012,8 \mathrm{a}$ & $56,0 \mathrm{a}$ & $1405,1 \mathrm{a}$ & $15,5 a$ & $3,5 b$ \\
\hline Ração farelada & $4874,5 a$ & $54,4 \mathrm{a}$ & 1258,7 & 14,0 & $3,8 \mathrm{a}$ \\
\hline Ração peletizada & $4555,1 b$ & $50,9 b$ & 1276,1 & 14,1 & $3,5 b$ \\
\hline
\end{tabular}

Médias com letras minúsculas distintas na coluna em cada fator diferem $(\mathrm{P} \leq 0,05)$ pelo teste $\mathrm{F}$.

ns = não-significativo; $\mathrm{Q}=$ efeito quadrático; $*(\mathrm{P} \leq 0,05), * *(\mathrm{P} \leq 0,01), * * *(\mathrm{P} \leq 0,001)$ 
àquele de $0,65 \%$, sugerido pelos manuais das linhagens Dekalb White e Bovans Goldline (Granja Planalto, 2005a,b), mas inferior ao valor de 0,79\% estimado por Silva et al. (2009) para as mesmas linhagens na fase de 1 a 4 semanas de idade.

Nesta fase de 5 a 11 semanas, a exigência dietética de met+cis é menor, principalmente porque houve boa formação das penas.

Os ganhos de peso total (Figura 1) e diário foram afetados pelos níveis de metionina+cistina total da dieta ( $\mathrm{P} \leq 0,001$ ) e foram maiores no nível de $0,64 \%$ de metionina + cistina total na ração, segundo os modelos quadráticos para ganho de peso total $\left(\mathrm{GPT}=-9909,9+34783 \mathrm{x}-26993 \mathrm{x}^{2}\right.$; $\left.\mathrm{R}^{2}=0,98\right)$ e para o ganho de peso diário (GPD $=-103,44+$ $\left.357,29 \mathrm{x}-277,37 \mathrm{x}^{2} ; \mathrm{R}^{2}=0,94\right)$.

Os níveis extremos de metionina+cistina total afetaram o ganho de peso das aves e o declínio simultâneo no consumo de ração $(P \leq 0,001)$ observado nesses níveis (Figura 1b).

De acordo com Silva et al. (2000b), os efeitos negativos, causados por níveis extremos de lisina na ração sobre o consumo sugerem relacionamento complexo envolvendo basicamente três processos simultaneamente: imbalanço, antagonismo e toxidez. Portanto, a redução no consumo das frangas nos níveis extremos de met+cis pode ter sido causada, a princípio, pelo desbalanço aminoacídico da dieta, mas é provável que o excesso de $10 \%$ dos aminoácidos sulfurados, acima da exigência das aves tenha provocado leve toxidez das aves, uma vez que a metionina é considerada, segundo Koelkebeck et al. (1991), um dos três aminoácidos mais tóxicos para as aves.

A conversão alimentar foi influenciada, de forma quadrática $(\mathrm{P} \leq 0,001)$, pelos níveis de metionina+cistina na ração (Figura 1). A conversão alimentar foi melhor nas
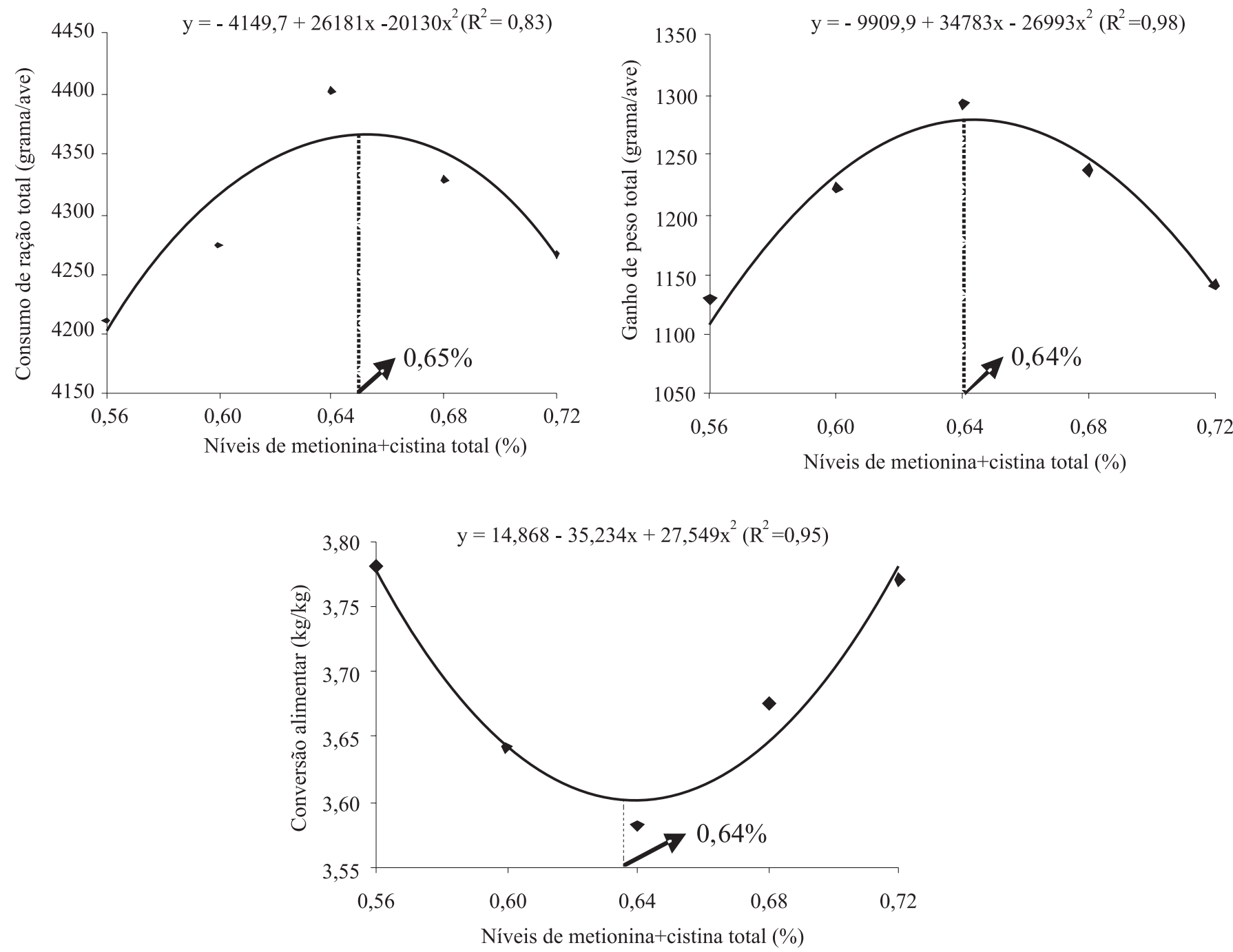

Figura 1 - Consumo total de ração, ganho de peso total e conversão alimentar de frangas leves e semipesadas alimentadas com rações farelada ou peletizada contendo diversos níveis de metionina+cistina. 
aves que foram alimentadas com a dieta com o nível intermediário de metionina+cistina. A exigência de metionina+cistina total, estimada com base na conversão alimentar, foi de $0,64 \%$ para frangas leves e semipesadas na fase de 5 a 11 semanas de idade.

A exigência média de metionina+cistina total para as aves das duas linhagens obtida neste estudo foi de $0,64 \%$, com base no ganho de peso total e diário e na conversão alimentar no período de 5 a 11 semanas de idade. Esse resultado difere dos valores de exigência em metionina+ cistina total para aves leves e semipesadas no período de 7 a 12 semanas de idade preconizados por Rostagno et al. (2005), de 0,55 e 0,54\%, e pelo NRC (1994), no período de 6 a 12 semanas, de 0,52 e 0,49\% de metionina+cistina, respectivamente. Os valores encontrados neste trabalho para as duas linhagens são superiores às recomendações desses autores.

O valor médio de exigência de metionina+cistina total para aves de reposição leves e semipesadas estimado neste estudo aproxima-se da exigência preconizada pelos manuais das linhagens Dekalb White e Bovans Goldline (Granja Planalto, 2005a,b), de 0,65\% para frangas no período de 4 a 8 semanas de vida, inferior ao estimado na fase de 1 a 4 semanas (0,79\%) por Silva et al. (2009).

A ração farelada contribuiu para maior $(\mathrm{P} \leq 0,01)$ consumo de ração total e diário. Entretanto, a dieta peletizada proporcionou melhor conversão alimentar $(\mathrm{P} \leq 0,01)$. Os ganhos de peso total e diário não foram afetados pela forma física da ração $(\mathrm{P}>0,05)$ (Tabela 3$)$.

O menor consumo de ração total e diário das aves alimentadas com a ração peletizada pode ser justificado pelo efeito glicostático, decorrente da melhora na digestibilidade do amido da ração, em decorrência do rompimento das organelas pelo efeito do calor, aumentando o aproveitamento dos carboidratos e da proteína.
Exceto para o peso vivo e o ganho de penas, houve efeito de interação entre os níveis de met+cis e a linhagem ( $\mathrm{P} \leq 0,001)$ sobre o peso e a porcentagem de penas (Tabela 4).

$\mathrm{O}$ peso vivo das aves foi afetado positivamente pelos níveis de met+cis na dieta $(\mathrm{P} \leq 0,001)$, conforme a equação: $\hat{y}=774,35+294,05 x ; R^{2}=0,78$. O mesmo efeito foi verificado com a interação dos níveis de met+cis e a forma física da dieta, para as mesmas variáveis ( $\mathrm{P} \leq 0,001)$. O peso vivo foi afetado pelos níveis de met+cis na dieta, conforme a equação de regressão quadrática, $\mathrm{PV}=-327,95+3765,8 x$ - $2712,3 x^{2} ; R^{2}=0,92$, e foi maior no nível de $0,69 \%$ de met+cis da dieta.

As aves da linhagem semipesada apresentaram maior peso vivo e maior peso de penas ( $\mathrm{P} \leq 0,001)$, o que confirma os resultados observados em trabalho realizado anteriormente, pelos mesmos autores, na fase de 1 a 4 semanas, quando as aves semipesadas também apresentaram maior peso de penas (Tabela 4). No entanto, as aves leves apresentaram maior ganho de penas que as semipesadas $(P \leq 0,05)$. A dieta farelada influenciou $(P \leq 0,01)$ o ganho de penas das frangas.

Houve interação significativa entre os níveis de met + cis total $\times$ linhagem para o peso e a porcentagem de penas $(\mathrm{P} \leq 0,001)$, com desenvolvimento máximo verificado no nível de $0,68 \%$, cujo efeito semelhante ocorreu nas interações entre níveis de met + cis total $\times$ forma física da dieta $(\mathrm{P} \leq 0,001)$, e entre a linhagem $\times$ forma física da ração $(\mathrm{P} \leq 0,001)$, com maior peso e porcentagem de penas para a dieta peletizada. Os coeficientes de variação para peso vivo, peso de penas, porcentagem, e ganho de penas foram de 3,575; 2,764; 3,479 e 3,820\%, respectivamente. A ração peletizada influenciou positivamente $(\mathrm{P} \leq 0,001)$ o peso vivo das aves às 11 semanas de vida. O peso e a porcentagens de penas das aves semipesadas foram influenciados de forma quadrática $(\mathrm{P} \leq 0,05)$ pelos níveis de

Tabela 4 - Peso vivo da ave, peso e porcentagem de penas e ganho de penas de frangas leves e semipesadas na 11 a semana de idade alimentadas com rações fareladas ou peletizadas contendo diversos níveis de met+cis total

\begin{tabular}{|c|c|c|c|c|}
\hline Met+cis total (\%) & Peso vivo da ave (g) & Peso das penas (g) & Porcentagem de penas (\%) & Ganho de penas (g) \\
\hline 0,56 & $926,6 \pm 107,4$ & $80,8 \pm 4,2$ & $8,7 \pm 0,6$ & $74,7 \pm 3,1$ \\
\hline 0,60 & $962,5 \pm 97,1$ & $89,2 \pm 10,9$ & $9,2 \pm 0,9$ & $73,9 \pm 2,5$ \\
\hline 0,64 & $971,3 \pm 115,7$ & $89,3 \pm 12,2$ & $9,1 \pm 0,5$ & $73,5 \pm 2,1$ \\
\hline 0,68 & $971,1 \pm 93,56$ & $92,1 \pm 10,2$ & $9,4 \pm 0,5$ & $73,5 \pm 2,6$ \\
\hline 0,72 & $981,1 \pm 115,1$ & $87,7 \pm 7,4$ & $9,0 \pm 0,7$ & $74,2 \pm 3,1$ \\
\hline \multicolumn{5}{|l|}{ Linhagem } \\
\hline Leve & $867,1 \pm 38,1 b$ & $81,0 \pm 7,1 b$ & $9,3 \pm 0,7 a$ & $74,3 \pm 2,9 a$ \\
\hline Semipesada & $1057,9 \pm 42,7 a$ & $94,6 \pm 7,3 a$ & $8,9 \pm 0,6 b$ & $73,6 \pm 2,3 b$ \\
\hline \multicolumn{5}{|c|}{ Forma física da ração } \\
\hline Farelada & $952,1 \pm 109,2 b$ & $86,0 \pm 12,2 b$ & $9,0 \pm 0,6 b$ & $74,5 \pm 2,4 a$ \\
\hline Peletizada & $972,9 \pm 99,8 \mathrm{a}$ & $89,6 \pm 6,6 a$ & $9,2 \pm 0,7 a$ & $73,5 \pm 2,8 b$ \\
\hline
\end{tabular}

Médias = letras minúsculas distintas na coluna e em cada fator diferem pelo teste $\mathrm{F}(\mathrm{P} \leq 0,05)$

$*(\mathrm{P} \leq 0,05) ; * *(\mathrm{P} \leq 0,01) ; * * *(\mathrm{P} \leq 0,001) ; \mathrm{ns}=$ não-significativo. 
met+cis da ração (Tabela 5). Os valores máximos de pesos e porcentagens de penas na linhagem semipesada foram constatados, respectivamente, com 0,65 e $0,64 \%$ de met+cis na ração, o que sugere que os níveis ótimos dos aminoácidos sulfurados para ganho de peso e conversão alimentar também são adequados para crescimento e rendimento máximos do empenamento.

Os níveis de met+cis total afetaram de forma quadrática o peso e a porcentagem de penas apenas para a linhagem semipesada $(\mathrm{P} \leq 0,05)$, com máximo peso e porcentagem de penas no nível de $0,68 \%$ de met+cis total. Os níveis de met+cis total não afetaram $(\mathrm{P}>0,05)$ o peso e a porcentagem de penas das aves leves.

A exigência para as frangas semipesadas foi de $0,65 \%$, com base nos resultados de peso e porcentagem de penas (Figuras 2). O peso de penas foi influenciado de forma quadrática $(\mathrm{P} \leq 0,05)$ pelos níveis de met+cis, dentro da ração peletizada (Tabela 6 ).

A interação dos níveis de met+cis e a forma física da dieta afetou apenas, de forma quadrática $(\mathrm{P} \leq 0,05)$, o peso de penas com o uso da dieta peletizada $(\mathrm{PP}=-356,2+$ $\left.1354,9 \mathrm{x}-1020,6 \mathrm{x}^{2} ; \mathrm{R}^{2}=0,53\right)$, com exigência estimada em $0,66 \%$ de met+cis para as duas linhagens, utilizando-se dieta peletizada. Esse valor é semelhante às recomendações dos manuais das linhagens leve e semipesada (Granja Planalto, 2005a,b).

Houve efeito de interação forma física da ração $\times$ linhagem da ave, proporcionando assim maior porcentagem de penas às aves leves (Tabela 6). O nível ótimo de met+cis obtido com base nas variáveis citadas anteriormente foi de $0,65 \%$, resultado que corrobora as recomendações do manual da linhagem (Granja Planalto, 2005a,b) de 0,65\% de met+cis para a fase de cria.

Os níveis de metionina+cistina influenciaram a postura do primeiro ovo, que ocorreu aos 113 dias de idade, início da 16aa semana, das aves no nível de 0,64\%. As aves que receberam a ração com o nível de met+cis de $0,56 \%$ atrasaram a maturidade sexual em aproximadamente dez dias em comparação às aves alimentadas com o nível de $0,64 \%$ de met+cis. Esse resultado sugere que aves melhor nutridas na fase de crescimento iniciam a postura mais cedo que aves submetidas à restrição

Tabela 5 - Peso e porcentagem de penas ao final da 11ํㅡ semana de idade de poedeiras alimentadas com ração farelada ou peletizada com diversos níveis de met+cis total

\begin{tabular}{|c|c|c|c|c|}
\hline \multirow[b]{2}{*}{ Nível de met+cis (\%) } & \multicolumn{2}{|c|}{ Peso das penas (g) } & \multicolumn{2}{|c|}{ Porcentagem das penas } \\
\hline & Ração farelada & Ração peletizada & Ração farelada & Ração peletizada \\
\hline 0,56 & $81,9 \mathrm{~B}$ & $79,7 \mathrm{~B}$ & $9,0 \mathrm{~A}$ & $8,5 B$ \\
\hline 0,60 & $82,7 \mathrm{bB}$ & $95,6^{\mathrm{a}} \mathrm{A}$ & $8,4 \mathrm{bB}$ & $10,0^{\mathrm{a}} \mathrm{A}$ \\
\hline 0,64 & $88,0 \mathrm{~A}$ & $90,6 \mathrm{~A}$ & $9,2 \mathrm{~A}$ & $9,1 \mathrm{~B}$ \\
\hline 0,68 & $94,2 \mathrm{~A}$ & $89,9 \mathrm{~A}$ & $9,6 \mathrm{~A}$ & $9,3 \mathrm{~B}$ \\
\hline 0,72 & $83,2 \mathrm{bB}$ & $92,2^{\mathrm{a}} \mathrm{A}$ & $8,7 \mathrm{~B}$ & $9,2 \mathrm{~B}$ \\
\hline Efeito & ns & $\mathrm{Q}$ & ns & ns \\
\hline
\end{tabular}

$(a, b)=$ letras minúsculas distintas, na linha, diferem entre si pelo Teste $\mathrm{F}(\mathrm{P} \leq 0,05)$.

ns = não-significativo; $\mathrm{Q}=$ efeito quadrático $(\mathrm{P} \leq 0,05) ; \mathrm{L}=$ efeito linear $(\mathrm{P} \leq 0,05)$.
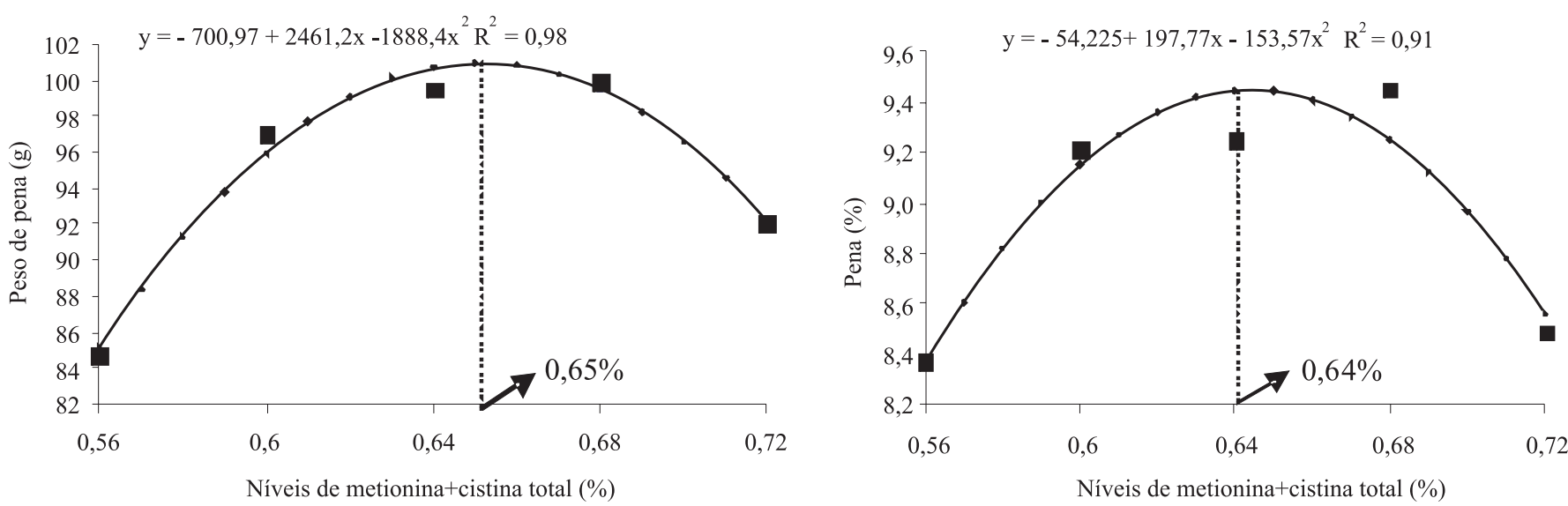

Figura 2 - Peso e porcentagem das penas de frangas semipesadas alimentadas com rações formuladas com diversos níveis de metionina+cistina. 
Tabela 6 - Peso e porcentagem de penas ao final da 11 a semana de idade de poedeiras leves e semipesadas alimentadas com ração farelada ou peletizada contendo diversos níveis de met+cis total

\begin{tabular}{|c|c|c|c|c|}
\hline & \multicolumn{2}{|c|}{ Peso das penas (g) } & \multicolumn{2}{|c|}{ Porcentagem da penas } \\
\hline & Leves & Semipesadas & Leves & Semipesadas \\
\hline \multicolumn{5}{|c|}{ Interação forma física da ração $\times$ linhagem da ave } \\
\hline Ração peletizada & $86,31 \mathrm{bA}$ & $92,97^{\mathrm{a}} \mathrm{B}$ & $9,76 \mathrm{aA}$ & $8,77 \mathrm{bB}$ \\
\hline \multicolumn{5}{|c|}{ Interação nível de met+cis $\times$ linhagem da ave } \\
\hline $0,56 \%$ & $76,9 \mathrm{bB}$ & $84,7^{\text {a } B}$ & $9,2 \mathrm{aA}$ & $8,3 \mathrm{bB}$ \\
\hline $0,68 \%$ & $84,3 \mathrm{bA}$ & $99,9^{\mathrm{a}} \mathrm{A}$ & $9,5 \mathrm{~A}$ & $9,4 \mathrm{~A}$ \\
\hline $0,72 \%$ & $83,4 \mathrm{bA}$ & $92,1^{\mathrm{a}} \mathrm{A}$ & $9,5 \mathrm{~A}$ & $8,4 \mathrm{~B}$ \\
\hline
\end{tabular}

a,b = letras minúsculas distintas na linha diferem $(\mathrm{P} \leq 0,05)$ entre si pelo teste $\mathrm{F}$.

$\mathrm{A}, \mathrm{B}=$ letras maiúsculas distintas na coluna diferem $(\mathrm{P} \leq 0,05)$ entre si pelo teste $\mathrm{F}$.

ns = não-significativo; $\mathrm{Q}=$ efeito quadrático $(\mathrm{P} \leq 0,05) ; \mathrm{L}=$ efeito linear $(\mathrm{P} \leq 0,05)$.

nutricional e confirma as afirmações de Silva et al. (2000a;b;c) e Vargas Jr. et al. (2004a,b) de que, com o avanço do melhoramento genético, as frangas de reposição tornam-se mais precoces, reduzindo a idade ao primeiro ovo, e níveis reduzidos de aminoácidos na alimentação durante o crescimento podem retardar o início da produção de ovos.

Não foi observado efeito de interação $(P \geq 0,05)$ entre os níveis de metionina+cistina, a linhagem e a forma física da ração (Tabela 7) sobre o consumo de ração, a produção de ovos, o peso e a massa de ovos, a conversão por massa de ovos e a gravidade específica da casca do ovo.

Os níveis de metionina+cistina da ração oferecida às aves de 5 a 11 semanas afetou de forma quadrática $(\mathrm{P} \leq 0,01)$ o consumo de ração, a produção, o peso de ovo, a massa de ovo e a conversão alimentar por massa de ovo $(\mathrm{P} \leq 0,001)$ de poedeiras leves e semipesadas no período de postura. Apenas a densidade aparente dos ovos não foi afetada $(\mathrm{P} \geq 0,05)$ pelos níveis de metionina+cistina da dieta.
O consumo de ração máximo das poedeiras foi obtido com a ração com $0,64 \%$ de de met+cis na fase de 5 a 11 semanas, conforme a equação: $\hat{y}=-9,9081+353,8 X-275,91 X^{2}$ $\left(\mathrm{R}^{2}=0,87\right)$. A produção e o peso dos ovos também foram influenciados $(\mathrm{P} \leq 0,05)$ pelos níveis de metionina+cistina da dieta oferecida às frangas de 5 a 11 semanas de idade. As exigências foram estimadas, respectivamente, em 0,64 e 0,63\% conforme as seguintes equações: $\hat{y}=-422,63+1586,9 X-$ $1232,2 X^{2}\left(R^{2}=0,92\right)$ e, $\hat{y}=-115,79+575,21 X-459,3 X^{2}\left(R^{2}=0,90\right)$.

Não houve interação níveis de met+cis $\times$ linhagem $(\mathrm{P}>0,05)$, níveis de met + cis $\times$ forma física da dieta $(\mathrm{P}>0,05)$, linhagem $\times$ forma física da dieta $(P>0,05)$. Os coeficientes de variação para consumo de ração, produção, peso de ovo, massa de ovo, conversão por massa de ovo e densidade aparente da casca do ovo foram de 2,779; 2,560; 2,706; 2,411; 3,789 e $0,257 \%$, respectivamente.

De acordo com Summers \& Lesson (1993), o peso corporal tem sido considerado a principal variável a influenciar o peso dos ovos. Níveis reduzidos e/ou elevados

Tabela 7 - Efeito residual dos níveis de met+cis total da ração fornecida durante o período de cria (5 a 11 semanas de idade) sobre o desempenho de poedeiras leves e semipesadas

\begin{tabular}{|c|c|c|c|c|c|c|}
\hline Met+cis (\%) & $\begin{array}{l}\text { Consumo de } \\
\text { ração (g/ave.dia) }\end{array}$ & $\begin{array}{l}\text { Produção } \\
(\%)\end{array}$ & $\begin{array}{l}\text { Peso do } \\
\text { ovo (g) }\end{array}$ & $\begin{array}{c}\text { Massa do } \\
\text { ovo (g/ave.dia) }\end{array}$ & $\begin{array}{c}\text { Conversão por massa } \\
\text { de ovo }(\mathrm{kg} / \mathrm{kg})\end{array}$ & $\begin{array}{l}\text { Densidade aparente da } \\
\text { casca do ovo }\left(\mathrm{g} / \mathrm{cm}^{3} \mathrm{H}_{2} \mathrm{O}\right)\end{array}$ \\
\hline 0,56 & 101,5 & 80,3 & 62,5 & 50,6 & 1,6 & 1,086 \\
\hline 0,60 & 101,5 & 84,1 & 63,2 & 51,3 & 1,5 & 1,086 \\
\hline 0,68 & 101,1 & 87,3 & 62,8 & 51,8 & 1,5 & 1,086 \\
\hline 0,72 & 101,8 & 80,7 & 60,2 & 50,1 & 1,6 & 1,085 \\
\hline Semipesada & 101,9 & $75,7 b$ & $65,8^{\mathrm{a}}$ & $49,8 b$ & $1,5 b$ & 1,092 \\
\hline \multicolumn{7}{|l|}{ Forma física } \\
\hline Farelada & 101,5 & 81,7 & 63,7 & 51,9 & 1,6 & 1,092 \\
\hline Peletizada & 101,8 & 80,4 & 63,9 & 51,2 & 1,6 & 1,095 \\
\hline
\end{tabular}

ns = não-significativo; $\mathrm{Q}=$ efeito quadrático; $*(\mathrm{P} \leq 0,05), * *(\mathrm{P} \leq 0,01), * * *(\mathrm{P} \leq 0,001)$. 
de metionina+cistina total na fase de cria (5 a 11 semanas) afetaram negativamente a massa de ovos, e o nível de $0,64 \%$ de metionina+cistina proporcionou melhor massa de ovos, conforme a equação: $\hat{y}=-68,745+379,33 X-297,31 X^{2}$ $\left(\mathrm{R}^{2}=0,88\right)$.

Melhor conversão alimentar por massa de ovos foi obtida com o nível de $0,63 \%$ de metionina+cistina da ração pelo modelo: $\hat{y}=8,0644-20,832 X+16,593 X^{2}\left(R^{2}=0,78\right)$, valor próximo ao nível médio de metionina+cistina (0,65\%) estimado pelo ganho de peso e pela conversão alimentar da fase de crescimento das frangas.

$\mathrm{Na}$ avaliação do desempenho durante o período de produção, a linhagem leve produziu mais ovos e maior massa de ovos $(P \leq 0,01)$, entretanto, as poedeiras semipesadas produziram ovos mais pesados e apresentaram melhor $(\mathrm{P} \leq 0,01)$ conversão alimentar por massa de ovos.

A forma física da ração utilizada no período de 5 a 11 semanas de idade não influenciou $(\mathrm{P} \geq 0,05)$ o desempenho subsequente (fase de produção) das poedeiras leves (Dekalb White) e semipesadas (Bovans Goldline). A interação nível de met+cis $\times$ linhagem $\times$ forma física da dieta não influenciou $(\mathrm{P} \geq 0,05)$ o peso e o rendimento de albúmen, gema e casca dos ovos (Tabela 8).

Os pesos de albúmen $(\mathrm{P} \leq 0,01)$, gema $(\mathrm{P} \leq 0,05)$ e casca $(\mathrm{P} \leq 0,01)$ foram afetados de forma quadrática: $\hat{y}=-1,7888+154,32 X-131,18 X^{2}\left(R^{2}=0,80\right) ; \hat{y}=-11,352+$ $87,131 X-68,69 X^{2}\left(R^{2}=0,63\right) ; \hat{y}=-6,336+40,908 X-32,143 X^{2}$ $\left(R^{2}=0,61\right)$, com exigências estimadas em 0,59; 0,63 e $0,64 \%$ de met+cis para cada variável, respectivamente. As porcentagens destas mesmas frações do ovo foram afetadas de forma linear pelos níveis de met+cis usados na fase de 5 a 11 semanas de idade, conforme as seguintes equações: $\hat{y}=69,422-6,2666 X\left(R^{2}=0,92\right) ; \hat{y}=21,754+4,349 X\left(R^{2}=0,95\right)$ e $\hat{y}=8,8239+1,9174 X\left(R^{2}=0,83\right)$, respectivamente.

Não houve interação níveis de met + cis $\times$ linhagem $(\mathrm{P}>0,05)$, níveis de met + cis $\times$ forma física da dieta $(\mathrm{P}>0,05)$, linhagem $\times$ forma física da dieta $(\mathrm{P}>0,05)$ para nenhuma das variáveis (Tabela 8). Os coeficientes de variação para pesos de albúmen, gema, casca e porcentagem de albúmen, gema e casca foram de 3,$500 ; 2,683 ; 2,332 ; 3,805 ; 1,572$ e $2,869 \%$, respectivamente.

De acordo com os resultados, o peso e a porcentagem de albúmen pioraram quando as frangas foram alimentadas de 5 a 11 semanas de idade com níveis mais elevados de aminoácidos na dieta (Tabela 8). O peso máximo da casca foi estimado com 0,64\% de met+cis na ração de 5 a 11 semanas, entretanto a porcentagem de casca melhorou com $0,72 \%$ de met + cis na ração de 5 a 11 semanas, o que coincide com a produção de ovos menores.

Entretanto, mesmo havendo diferenças na porcentagem de casca, a gravidade específica não variou com as rações utilizadas na fase de cria.

A estimativa indireta de exigência de met + cis da fase de 5 a 11 semanas para o máximo peso de albúmen foi menor que a exigência para o ganho de peso e a conversão alimentar no período. O nível máximo do peso e a porcentagem de gema foram estimados, respectivamente, em 0,63 e $0,72 \%$ de met+cis na ração de 5 a 11 semanas de idade das frangas. A maior porcentagem de gema verificada com o aumento dos níveis de met+cis pode estar relacionada à formação da colina a partir de metionina, somada aos fosfolipídios para formar as lipoproteínas da gema.

O nível máximo do peso e da porcentagem de casca foi estimado, respectivamente, em 0,64 e $0,72 \%$ de met+cis na

Tabela 8 - Qualidade interna dos ovos de poedeiras leves e semipesadas alimentadas com rações fareladas ou peletizadas contendo diversos níveis de metionina+cistina total durante a fase de cria

\begin{tabular}{|c|c|c|c|c|c|c|}
\hline & \multicolumn{3}{|c|}{ Peso (g) } & \multicolumn{3}{|c|}{ Rendimento (\%) } \\
\hline \multicolumn{7}{|c|}{ Nível de met+cis (\%) } \\
\hline 0,56 & 43,3 & 15,8 & 6,4 & 65,9 & 24,1 & 9,8 \\
\hline 0,60 & 43,7 & 16,2 & 6,6 & 65,7 & 24,3 & 9,9 \\
\hline 0,64 & 43,6 & 16,4 & 6,7 & 65,2 & 24,6 & 10,1 \\
\hline \multicolumn{7}{|l|}{ Linhagem } \\
\hline Leve & 42,4 & 16,2 & 6,5 & 65,0 & 24,9 & 10,0 \\
\hline Semipesada & 43,2 & 15,8 & 6,5 & 65,8 & 24,1 & 10,0 \\
\hline \multicolumn{7}{|c|}{ Forma física da ração } \\
\hline
\end{tabular}

$\mathrm{Q}=$ efeito quadrático; $\mathrm{L}=$ efeito linear; $\mathrm{CV}=$ coeficiente de variação. $*(\mathrm{P} \leq 0,05),{ }^{* *}(\mathrm{P} \leq 0,01),{ }^{* *}(\mathrm{P} \leq 0,001)$. 
ração de 5 a 11 semanas de idade das frangas. Os resultados da fase de produção mostraram que o pico de postura também é afetado pelos níveis de met+cis utilizados na ração de 5 a 11 semanas de idade, de modo que as frangas com crescimento normal apresentam pico mais alto de produção de 22 a 40 semanas de idade em comparação àquelas recebendo rações deficientes ou com excesso dos aminoácidos sulfurados.

\section{Agradecimentos}

À Granja Planalto LTDA, pela doação das aves.

À Empresa Guaraves Alimentos, pelas análises laboratoriais

\section{Conclusões}

As exigências de met + cis total para bom desempenho de poedeiras leves e semipesadas na fase de crescimento são de $0,65 \%$ ou 320 e $364 \mathrm{mg}$ de met+cis total/dia, respectivamente. No período de crescimento, a linhagem semipesada tem desempenho melhor que o da linhagem leve, mas as poedeiras leves produzem maior número de ovos. O uso de dietas peletizadas reduz a ingestão de ração fornecida às frangas leves e semipesadas de 5 a 11 semanas, mas não tem efeito residual sobre o desempenho na fase de postura.

\section{Literatura Citada}

GRANJA PLANALTO. Guia de manejo de poedeiras Bovans goldline. Uberlândia, 2005a. 37p.
GRANJA PLANALTO. Guia de manejo de poedeiras Dekalb white. Uberlândia, 2005b. 35p.

KOELKEBECK, K.W.; BAKER, D.H.; HAN, Y. et al. Research note: effect of excess lysine, methionine, threonine, or tryptophan on production performance of laying hens. Poultry Science, v.70, p.1651-1653, 1991.

NATIONAL RESEARCH COUNCIL. Nutrient requeriments of poultry. 9.rev.ed. Washington: National Academy, 1994. 155p.

ROSTAGNO, H.S.; ALBINO, L.F.T.; DONZELE, J.L. et al. Tabelas brasileiras para suínos e aves: composição de alimentos e exigências nutricionais. Viçosa, MG: UFV/DZO, 2000. 141p.

ROSTAGNO, H.S.; ALBINO, L.F.T.; DONZELE, J.L. et al. Tabelas brasileiras para suínos e aves: composição de alimentos e exigências nutricionais. 2.ed. Viçosa, MG: UFV/DZO, 2005. 186p.

SILVA, E.L.; SILVA, J.H.V.; BERTECHINI, A.G. et al. Exigência de metionina+cistina para aves de reposição leves e semipesadas de 1 a 4 semanas de idade alimentadas com rações farelada e triturada. Revista Brasileira de Zootecnia, v.38, n.3, p.500-507, 2009.

SILVA, J.H.V.; ALBINO, L.F.T.; ROSTAGNO, H.S. et al. Exigência de lisina para aves de reposição de 0 a 6 semanas de idade. Revista da Sociedade Brasileira de Zootecnia, v.29, n.6, p.1777-1785, 2000a.

SILVA, J.H.V.; ALBINO, L.F.T.; ROSTAGNO, H.S. et al. Exigência de lisina para aves de reposição de 7 a 12 semanas de idade. Revista Brasileira de Zootecnia, v.29, n.6, p.1786-1794, 2000b.

SILVA, J.H.V.; ALBINO, L.F.T.; ROSTAGNO, H.S. et al. Exigência de lisina para aves de reposição de 13 a 20 semanas de idade. Revista Brasileira de Zootecnia, v.29, n.6, p.1795-1802, 2000c.

SUMMERS, J.D.; LEESON, S. Factors influencing early egg size. Poultry Science, v.62, p.1155-1159, 1993.

UNIVERSIDADE FEDERAL DE VIÇOSA - UFV. Sistema de análise estatística e genética - SAEG. Viçosa, MG, 1993. 59p.

VARGAS JR., J.G.; ALBINO, L.F.T.; ROSTAGNO, H.S. et al. Níveis nutricionais de cálcio e de fósforo disponível para aves de reposição leves e semipesadas de 13 a 20 semanas de idade. Revista Brasileira de Zootecnia, v.33, n.5, p.1263-1273, 2004a.

VARGAS JR., J.G.; ALBINO, L.F.T.; ROSTAGNO, H.S. et al. Níveis nutricionais de cálcio e de fósforo disponível para aves de reposição leves e semipesadas de 7 a 12 semanas de idade. Revista Brasileira de Zootecnia, v.33, n.4, p.936-946, 2004b. 